\title{
Divine Eros
}

\section{and Divine Providence in Proclus' Educational} System

\author{
CHRISTOS TEREZIS / Patras / \\ MARILENA TSAKOYMAKI / Patras /
}

\section{Introduction}

The aim of the present paper is twofold. Firstly, it will attempt to describe the content, the extent and the intentions that form the relation which according to Proclus ought to be developed between the educator and the receiver of education. Secondly, it will present the methodological steps through which all of the above must be articulated and realized according to the philosopher. The text used in this study is the commentary of Proclus on the Platonic dialogue Alcibiades I, whose subject is the beginning of the communication between Socrates and Alcibiades. The Neoplatonic philosopher finds in this communication more than one meaning of educational relation. He reveals critical anthropological and existential aims guided, additionally, by divine and metaphysical inspirations. More specifically, the question is how Alcibiades as a student will be able to reveal the deepest cores of his existence, his spiritual potential, his ethical foundations, and his real interests in life. At the same time, though, the philosopher estimates that the ultimate target for 
Alcibiades is not only to be guided to self-knowledge, but also to realize the orientation which gives an essential meaning to the human course. The following parts of this study present Proclus' references to the criteria that Socrates fulfils as an educator and as a lover, in order to approach Alcibiades through the terms of high anthropological deontology. This is a course whose culmination is located in the divine spirit, which, as an expression of the divine providence, offers to man the integrity and the diachronic of the objective values. Inspired, thus, by divine interventions, Socrates becomes a 'divinely inspired' lover and educator. Regarding all the aforementioned aspects, Proclus refers to certain general educational positions, using always Socrates as a cause and as a starting point. ${ }^{1}$

\section{The attributes of the Divine and Vulgar Lover $(46,14-49,15)$}

Having examined within a general frame the issues regarding the communication on love matters, Proclus continues by beginning to research two specific issues referring to the communication between Socrates and Alcibiades. Firstly, he enquires into the cause of wonder of Alcibiades regarding the zeal of Socrates to remain close to him, retaining in his position all the pure characteristics of love when all of the other lovers have left. Secondly, he examines how the Athenian dialectic perceives the intellectual condition of the politically ambitious young man. These questions are systematically set to be examined using as a cause the evaluation of the human criteria, which, as presented by the Neoplatonic philosopher, are not always characterized by an austere analysis.

In the beginning, it is noted that the less perfect persons are accustomed to evaluate their efforts and the activities of their internal world according to their duration and not according to the perfection of their quality. They lay, therefore emphasis on quantitative criteria rather than on intellectual and creative ones. Thus, the following simple remark in the form of a rhetoric question is set immediately after: Is it not easily ascertained that many invite someone who has disposed enough time in the company of teachers, a skilled craftsman or a specialized scientist - an expert for matters with which he has dealt with extensively? The following remark is of a critical order and proceeds into further evaluative categorization pointing out, in a reversed comparison to the previous concept, the argument that it is not surprising that a cleverer person requires less time and effort in order to achieve the completeness of his self. Still, those who do not possess the capability to judge the form as such, i.e. the authentic condition, and the tendency of a person towards a specific conquest, consider their time to have been given by nature as an adequate evidence of effectiveness. ${ }^{2}$ Due to this fact, that the majority has the habit

\footnotetext{
${ }^{1}$ For the content of the Alcibiades I, see the extensive introduction of Segonds (1985: VII-CXXXIX), where the relevant commendatory tradition with reference to this platonic dialogue is presented analytically. See also Bastid (1969: 35-44).

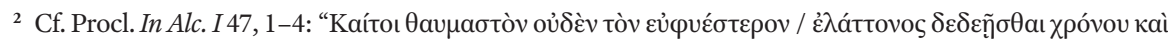

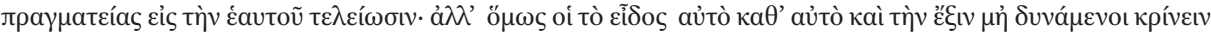


of judging every circumstance in this manner, by dire necessity Alcibiades as well would wonder about the duration of the love of Socrates, as to what the latter is in its origins. In other words, must the duration be evaluated in quantitative or qualitative criteria? This is a problem that occurs from the comparison of the Athenian dialectic with the other lovers of Alcibiades. Furthermore, it is pointed out that there can be no doubt that the Athenian philosopher, knowing the young age of Alcibiades, would aim to explain to him his query regarding the reason for which he clearly expressed in the present moment for the first time his providence, and retained for an extensive period of time a loving interest towards him. At this point, in a way, we would propound a pedagogical strategy, which is immediately connected to the specific - in terms of the realistically qualitative - moment of the expression of the personal reference.

Proclus, then, shifts his investigations to general matters of ethical reference. He examines for which reasons the intemperate could never make himself worthy of the epithet prudent (moderate), the unjust - of the epithet just, and the coward - of the epithet brave. More specifically, he emphasizes the reasons that make it impossible for the same person to receive at the same time two different attributes. Such a double characterization would obviously be contradictory and would, thereby, create problems in the evaluative process. It is also noted, that the annoying (vulgar) regarding their love-affair issues and also those who have never attained in the correct sense such an attribute desire to be called lovers and to participate in the characterization of this divine condition. The same is valid for those having a different target in life and, moreover, for those adopting a hostile behavior towards those possessing the above mentioned attribute. Here, Proclus notes the specific distinction that exists between the two attitudes referring to love issues. On the one hand, the divine lovers guide their beloved ones to the divine and to the in any given aspect illuminant and one-like in nature, while the others, the vulgar ones, guide the souls of their beloved ones to the godless, dark and fragmental. ${ }^{3}$ The dialectical contradiction is here evident through terms of an extreme confrontation which is also irreconcilable. These are two completely different existential horizons that refer to two different anthropological paradigms.

According to the Neoplatonic philosopher, the cause of the above discussed difference lies in the fact that the aim and the habits of the intemperate one are completely different from those of the prudent one. Certainly, all lovers have the same aim, e.g. becoming familiar with the beautiful. But the forgetfulness and the ignorance of the primarily beautiful lead the vicious-inferior lovers to the material kind of beauty, which entails their degeneration as lovers. The deviation is, thus, also based on specific epistemological deficits. Therefore, the lowest beauty possesses the same name as the primarily

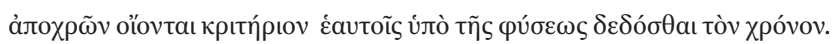

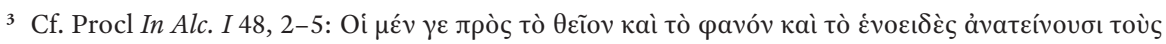

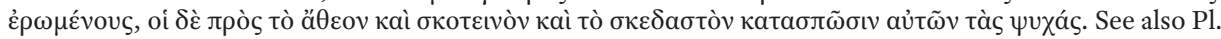
Phdr. $256 \mathrm{~d} 8$ and Procl. Plat. Theol. I 107, 17. 
and at a superior grade beholder of this attribute, even though it has been deprived of its original nature, for the beauty is to be found in the form, while its deviation is mixed with the non-form and the ugly, i.e., the inferior lover claims the same name with the first, as he is relevant to the ultimate inferior beauty. However, according to Proclus, in specific cases the free association between the two situations beauty-love is presented to occur as normal through other conditions besides their names. Firstly, it is said that the intemperate and the prudent are characterized by completely opposite tendencies and actions. And obviously, precisely this difference is the explanation, as each and everyone commences from a different ethical, epistemological, and theoretical paradigm. The situation, though, presents a different image when the discussion refers to lovers. All lovers, since they are possessed by enthusiasm ( mania), acquire the same experience, although they differ as to the superior or inferior kind of enthusiasm, and more explicitly as to the manner of their participation in this qualitative condition. The divine lovers participate in the pure nature of the love affair communication, while the others in a vulgar one. As each of them (irrespective of his reasons and aims) is directed in a 'manic' way towards the beautiful, he also participates in the same name. The complex way of this enthusiasm and the forms of the beautiful certainly diversify the divine from the vulgar lovers, but the direction can be characterized as common.

Still, for Proclus there is also a third argument: The most divine things due to their abundant power regulate their inferior derivations, transmitting, thus, to their hypostasis a certain reflected appearance of their own familiar original property. And while prudence cannot act in this way upon intemperance, the divine loving friendship, precisely because of the fact that it is prudent, gives something to its image and transmits to it various faint traces. For that reason, the above discussed trace is called an image and participates in the same name, because in every case the images desire to receive the same name with their exemplars. ${ }^{4}$ Hence, the principal of analogy can here easily be applied along with all its multiple meanings, which are clearly declarative of the differences in terms of the qualitative and quantitative possession of an attribute.

\section{The Constitutional Position of Love $(49,16-53,18)$}

When proceeding to next issue, Proclus notes that it has already been mentioned that the real lover is the divinely inspired one, as Socrates himself advocates, proving himself as the only lover really interested in the true Alcibiades. The reason for that is that Socrates is a lover of the soul, as opposed to the those who "destroy each other for the sake of a phantom" as Homeric poetry has it (Iliad E, 451-452). The result is that when they

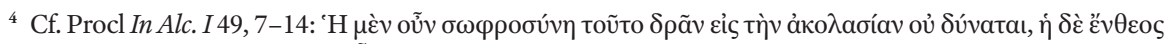

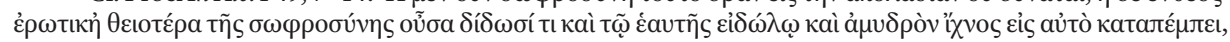

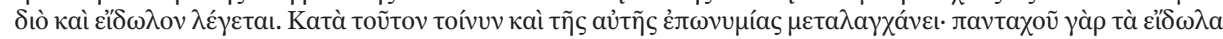

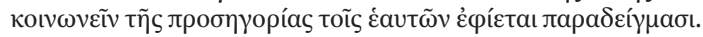


see the phantom of beauty losing its splendor they are guided to other choices different from the previous ones. Already in the first sentences, Socrates presents himself as the only lover of Alcibiades, continuing to honor his beloved one in a way different from the others, and being presented like a 'daimon' (spirit), a guardian or god that makes provision for him from outside. The reason for this strong presence is that the superior in every rank of beings is of one and exclusive meaning, even if there is a crowd following it. The concept for the receivers is justified in the following way: this crowd, even if it possesses a certain grade of good, owes its acquisition to the unification with the superior. If tough, anything is put on the same rank with something not possessing the attribute of the good, this last entity cannot be regarded as unique. The property of the 'Good' is the only one considered to be exclusively possessed. Thus, Socrates according to the previous argument is viewed as the only authentic lover, superior to the crowd of the common lovers: The criterion for this position-assessment is that the latter cannot be ranked or have the prerequisites or the intentions related through the perspective of virtues-values to the Athenian philosopher due to the dissimilarity between them. ${ }^{5}$ Once more, therefore, Socrates is shown here, under the aforementioned principal terms, as the only lover of Alcibiades, a responsibility parameter that even the latter will recognize through the realization of his self, and through the separation of the soul from the body, which in turn form two distinctive factors between them. Only then, will he be able to distinguish the exemplar, the image, and the reality of love along with the false named lover which adopts or attempts to acquire the epithet of the divinely inspired one. It is the moment when he will be able to specify his definitions and his assessments in a sum of conditions, i.e., complicated situations, which he comes across and which he is called to categorize into distinctive notional frameworks.

Returning to the issue of eros of the most intimate matters, Proclus notes that we cannot consider this god as worthy of being ranked among the first beings or among the last ones. His characterization in the first case is based on the fact that the object of love is to be found further than the love itself. On the other hand, it cannot belong to the last ones because the subject acting in love participates in the situation that he himself creates and, thus, is transformed through its life and presence. Therefore, this god must be placed between the object of love and the lovers, i.e., must follow the beautiful and come before the ones that express a love disposition. It has to constitute an in-between condition. Here, Proclus poses three questions: where did love initially take form? how does it advance towards all things that exist? and along with which units (i.e. principal ontological conditions) is it transferred into matter? According to the Neoplatonic philosopher, it has to be taken under consideration that the hypostases in the conceivable and nonrevealing gods are three. He transfers, therefore, the issue to the basic principles

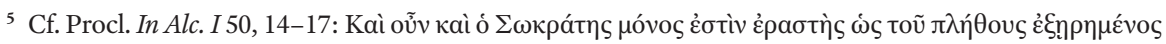

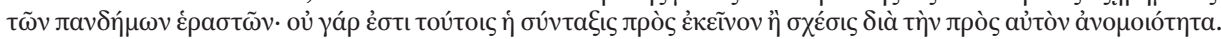
It should be noted that Proclus presents Socrates approaching Alcibiades in the most appropriate moment. For a discussion of the way in which the Neoplatonic philosopher treats this subject, see Moutsopoulos (2003). 
which he adopts for the structure of the metaphysical world. The first one is characterized by the 'Good', the second one - by the Wise, where the first intellect is, and the third one is characterized by the Beautiful, where the most beautiful of the intellectual is located, as it is referred to in the Platonic Timaeus (30 d 1-2). Moreover, according to theses perceivable causes, there are three units, by cause and unity, existing in the intellectual, firstly though appearing in the ineffable order of the gods: faith, truth and love: The first one founds the universe and bestows upon it the good, the second one reveals the knowledge that coexists in all beings and the third one assists in the return and the union with the ontological nature of the beautiful. This triad is transmitted from this starting point to all divine orders and reflects in everything the union with the metaphysical world. ${ }^{6}$ It is revealed in a different way in each order connecting its powers with the relevant attributes of the gods. Therefore, the above discussed specification excludes the mechanistic identity. Sometimes, it is expressed in an unspoken, unfamiliar and unified manner, whereas in other times it is expressed in a cohesive and connected way. In yet other circumstances, it is expressed in a perfective and formative manner, or even in an intellectual and fatherly one. Still, in different terms, it is also presented as a moving, life-giving and poetical (creational) power, or in a dominant and assimilative way, or in an absolute and clear one or, lastly, in a multiplicative and divisive one. Thus love extends from the intellectual to the worldly, assisting in this way to their return towards the divine beauty. On its part, the truth illuminates everything with knowledge, while faith positions every being in the good.?

For this reason, the gods advice the theurgists on how to attach themselves to the god of love through this triad. The intelligible, therefore, precisely because of its absolute unification, does not need an intermediate love. Wherever though, there is the unification and distinction of beings, love appears as an intermediate condition. In connects the divided, it unifies those that come before and after it, it contributes to the return of the second one to the first one and it guides to perfection even the most imperfect ones. Hence, it secures an unbreakable unity and brings the necessary amendments. In a similar way, the divine lover, imitating the god that he reaches in his esotericism, detaches himself from the superficial of the material and guides himself to the higher kind of human conditions, perfects the imperfects and renders effective the aim of those who are in need to be guided in their existential completeness. By contrast, the foul lover attracts the souls to the depths of matter, misguides them from the divine and pushes towards the falsehood and ignorance, filling the soul of his lover with various kinds of phantoms.

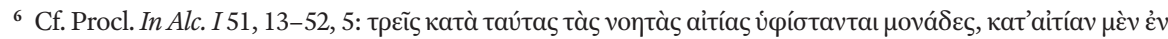

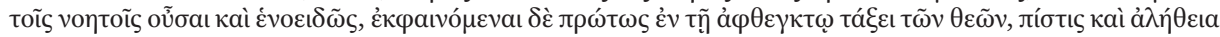

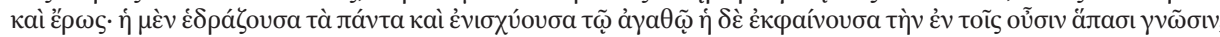

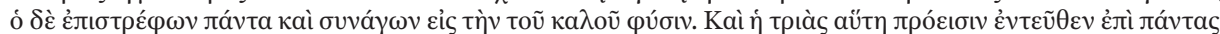

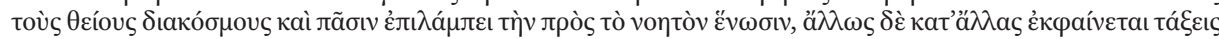

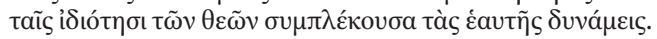

${ }^{7}$ For the sources of the above mentioned terms, see the comments of Segonds (1985: 151-152). 
Consequently, the latter is surrendered not to the 'divine fire' but to the birthing heat of the matter and to the darkness of the material. ${ }^{8}$ In these narrative terms, the contradictions between the two types of lovers, that are dialectically irreconcilable, become clearer, as elements of the theoretical and the practical reason are also introduced.

\section{Divine and Spiritual Providence $(53,19-56,4)$}

In his next argument, Proclus notes that there are mainly two elements in the divine and spiritual providence towards the secondary one, in terms of ontological and evaluative order: 1) providence runs through everything from the superior to the inferior, without leaving even the slightest trace of participation in its projection (image) and 2) it is not possessed as a presence through any of the beings that it itself administrates, nor is it infected by their nature, or confused with their hypostasis. It is not mixed with those that constitute object of its providence (as it is not possible, by nature, for the divine and the spiritual to test the trouble of every human or any other soul). At the same time though, it does not abandon any of the inferior beings without order and discipline due to its distinctive superiority towards all things secondary. Hence, both situations are sustained. All things perceive providence which regulates everything, surpassing in all aspects the ontological position which these possess. It remains, thus, of good and pure nature, putting the universe in order but without relating itself to the things it regulates. At the same time, it runs through all things without being identified with any one of them. Proclus observes that Plato ascribes this divine and spiritual providence to the good willed providence of Socrates towards the less perfect, which, an illuminated teacher retains towards the beloved one as available whenever needed for the care of the latter. Simultaneously, though, it is secluded, pure and untouched by all those social elements that surround him. ${ }^{9}$

The fact that Socrates was the first friend of Alcibiades when everyone else ceased to express interest towards the latter stands as a strong evidence for the guardianship concerning the manner in which the young man should compose his life. The fact that during his long presence he did not speak to him shows his non-invasive care for his inferior companion, through non-normative terms. As an argument the latter cites the old and traditional position: the first contact between people begins with a dialogue. The fail-

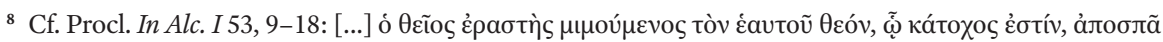

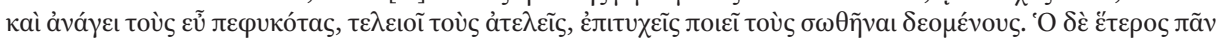

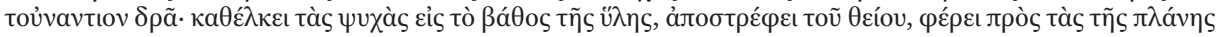

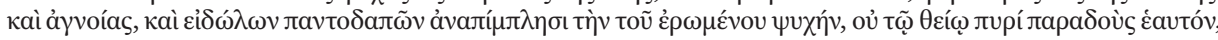

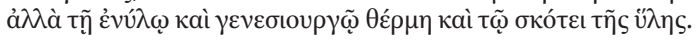

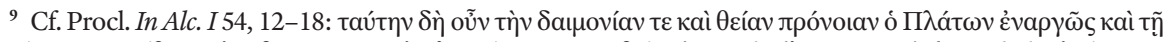

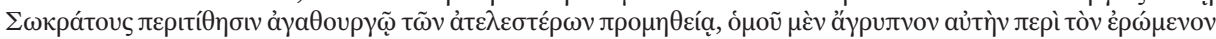

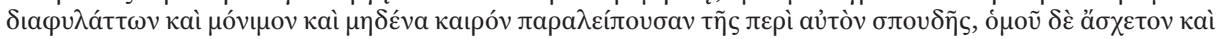

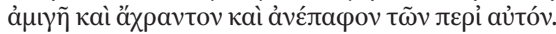


ure to secure even such form of communication with his favourite reveals the superiority of Socrates just as does his refusal of the inferior, without though getting involved with further anthropological devaluations. At the same time, he is both present and absent, interested and distanced, distant and close to the youth. Through the return to the major, the following question is brought forward: if the behaviour of divine people is interpreted in this way, could the respective one of the gods and good spirits be interpreted in another way? The analogies are here clear. Though they are present in everything, they surpass it, and though they have offered fullness through themselves to the lowest, they do not mingle with their hypostases, and while they are extended everywhere, they do not place their existence into any specific territory. What could we assume with regard to the myths about the gods who are portrayed as in love with their descendants, e.g. Zeus Persephone or Aphrodite? Maybe this love provides and gives fullness to the lovers leading them to their coherence and completion?

Bringing the problem of love itself, the question arises whether it is good and pure in nature. But here also the definitions prove restrictive. Hence, which derivation can we ascribe to this love idiom with respect to the human souls, if we do not consider that it pre-exists in the gods themselves? The question is clearly a rhetorical one since generally everything good, besides souls, owes it cause of derivation to the gods. Regarding this argument Plato relates in the Laws $(631 \mathrm{~b}-\mathrm{c})$ that the exemplars of all virtues and corporal goods pre-exists in the divine world, the examples being health, power, justice and moderation. ${ }^{10}$ Moreover, we may assume that the primary cause of love is found in the gods and it is 'offered as a divine gift' as argued by Socrates in the Phaedrus (244 a). Thus, the gods express their erotic reference to the gods but through the following specifications: the elderly fall in love with the younger in the form of providence, while the younger fall in love with the elder in the form of return towards the latter, precisely as the providers do towards of the above discussed providence. In the metaphysical system, the mutuality forms an ongoing reality through distinctions and through analogies corresponding to each case the particularities are kept inviolate. ${ }^{11}$

\section{The Distinction between the Divinely Inspired and the Vulgar Lover $(56,5-59,22)$}

When examining systematically the cause of Socrates' silence, Proclus argues that one should notice that in the area of the gods the unspeakable precedes the spoken, the unutterable - the feasibly uttered and the silent - that which can come forward through words and voice. The negative precedes the affirmative. This concept of justification is based

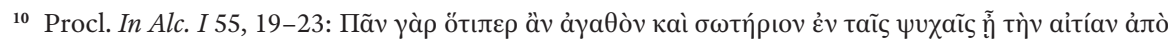

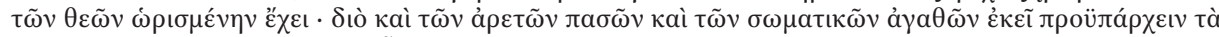

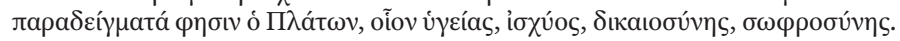

11 See also Procl. In Rep. I 136, 23-25. 
on the fact that Socrates, having assimilated the divine to himself, declares his provision towards his beloved one through a silent position, as the latter constitutes the first appropriate element of love, in the same way that it exists in the rank of gods, which in its turn is characterized by silence. This situation of negativism and of mysticism is, thus, consistent in terms of time. Hence, the divinely inspired lover is in need of firstly entrusting his guardianship of his beloved one to the divinely 'inspired silence', before he communicates with him through words. Because of this, he will be able to assimilate himself to the god, and on the other side, he will be able to turn the young man towards the question about the silence via which he is attempting to approach him. This action will release Alcibiades from his passive condition and transform him into an active person. This is how Socrates behaves, while for the vulgar lovers it is explained that they become 'mobbing'. The word 'mob' obviously signifies a crowd. But this is an indeterminate mob that is confused and without order and does not function like the chorus or the demos which follow and apply a specific normative order. The basis for this distinction is that demos constitutes a group of united people, while mob is a fragmented crowd. This difference constitutes an important criterion, since in every conversation on constitutions we clearly differentiate between ochlocracy and democracy. ${ }^{12}$ The former is characterized by lack of any order, illegality and wrong actions, while the latter is based on laws that order various activities in a rational way and compose a reasonable and cohesive collective system. The vulgar behavior, therefore, reflects a confused and careless kind of life, which drags the lover towards the materialized, fragmentary and manifold kind of variety of emotions that on their own possess an advanced tendency for vulgar conquests. In addition, as it is known, the Timaeus (42 c) calls every kind of irrational behavior a confused and disorderly mob: 'a large and later thronging mob composed of fire, water, air and earth, a noisy and irrational mass'. Therefore, the term 'others' reveals the discordant life of the vulgar lovers. In the same way, the fact that they become vulgar reveals the insulting behavior of the many towards the young man, and, consequently, his being debased to the fragmented and material kind of life. Moreover, it can be pointed out that they not only maintain a divided and discordant relation between them, but also they fill the young man with vice and superficial actions instead of using the power of love. From a contrary point of view, 'love sets aside loneliness (estrangement) and through familiarity fills in a capital grade people' as Agathon advocates in Symposium (197 d). The vulgar lovers are characterized by division and discord between them, extending, thus, the discussed estrangement also to the beloved one. This results from the fact that the vulgar is by nature strange and sad, which explains why it cannot acquire any friendly

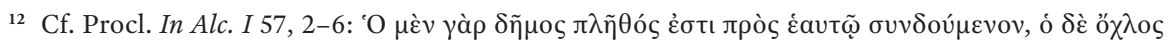

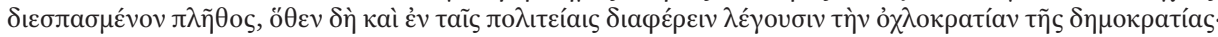

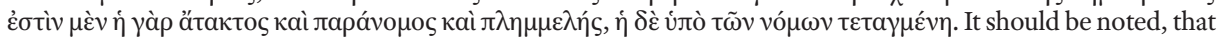
the distinction between the two kinds of political organizations is interesting but not to be found in the political works of Aristotle. 
relations with the situation in which it intervenes. This is precisely the kind of common lover that suffers from vices which deconstruct communication.

In the course of the argument, there emerges an eulogy for the personality of Alcibiades in this moment of his dialogue with Socrates when he admits his company with the others, but despite their admiration towards him, distances himself from them because he regards their emotional behavior as vulgar and distasteful. However, despite his participating in conversation with the vulgar lovers, he keeps away from various symposia and other distasteful conditions of communication which lead to bad forms of life. Thus, we have the difference in the nature of Alcibiades with respect to one of others of the same age and the following point is put forward as an argument regarding the latter: when we train ourselves to pleasure and pain without avoiding such emotions and without remaining completely inexperienced in them, we make sure that we secure the 'medium', surpassing their excess and disorder - the same can be observed in love matters when the superior strives for the integral virtue in the company of vulgar lovers. ${ }^{13}$ The analogy is precise because surpassing the annoyance of these lovers and prevailing against their irrationality reveal the power of natural and personal conditions to repudiate flattery and life bound to pleasure. With such characteristics of his nature, Alcibiades proves worthy of Socrates' love, as he frees himself from the influence of lover at such a young age and expresses his admiration for the interest in the great dialectic. And, as the Athenian stranger (Laws 648 c 7-650 b 4) guides the young to strong drinking, considering this tactic a test against their vices and rendering it a judge of the movements within them, Socrates presents himself as a regulator of the intoxication that accords to the age of the young man, and as a judge not only of him but also of his vices and of the lovers that live in an analogous, ethically degenerated, manner. Having ascertained that Alcibiades has surpassed all of the above, including the disgraceful, deceitful and devious life of the many, Socrates invites him to communicate with him, while also revealing to him the true nature of love, the benefit that results from its expression and the aim of the activity according to virtue, which in its turn directs towards the best ethical conditions, i.e., rising to practical Reason. ${ }^{14}$

\section{Evaluative Assessments for the Divinely Inspired and the Vulgar Lover}

$(60,1-63,12)$

In the next thematic unit, Proclus repeats that Socrates has provoked wonder to the young man through his words due to the stability of love towards him and also due to

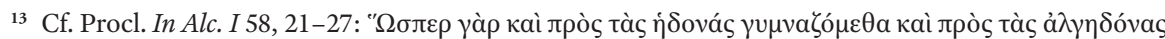

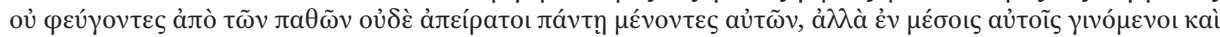

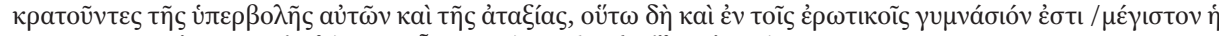

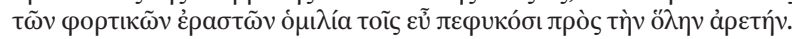

14 See also Arist. NE 109ß8 16-17. 
the pure, detached and motiveless providence towards his existence. He argues in extent that nothing else could be regarded as more divine in human life than divine providence towards the secondary beings, which surpasses any qualification. The property of providence is to range through everything without losing its self-composure, while being present in everything, remaining established in itself. This forms the most paradoxical of the theories regarding the content of providence. If we project the issue onto human relations, it can be set as follows. A man remains in stable relation to himself, while at the same time turning his attention to persons lesser than him. ${ }^{15}$ Socrates continues to astound Alcibiades by combining the cause of human activities with the spiritual and, thus, showing himself as admirable not only as a plain human but also as acting in accordance to the spirit that possesses a qualification superior than any human virtue, i.e., the spiritual inspiration. Consequently, the love of Socrates is far from that of the other lovers. And the difference is due to the fact that they guided Alcibiades to irrationality and to the matter, while Socrates lifts him up to reason and to the spirit. Divine love is considered to be elevating, beneficent, dispensing of perfection and also causing intelligence and life according to the latter. This is due to the fact that 'one cannot easily find a better help to philosophy other than love', as Diotima says in Symposium (212 b). It is shown, therefore, that Socrates, being inspired by his spirit, stimulates Alcibiades to astonishment and multiplies his awe for philosophy.

It is quite consistent for Socrates to act in this way. The idea is based on the argument that many similar occasions of amazement attract us to empathize with the good. In the holy ceremonies some inspirations that provoke awe precede the performance of the rites by submitting the soul to the divine through what is said or revealed. In the same way, in the threshold of philosophy, the guide provokes astonishment and wonder in the youngster about himself in order for the preceding discussion to invite him to gradually participate in the life of philosophy. This process is considered obligatory and applied at to major extent in the case of arrogant people. The latter applies because such an attribute is considered to be correct by the mob, although it forms an obstacle for greater people. Here, the distinction between the superficial and the normative criterion is clear. In order to avoid Alcibiades' contempt, Socrates quickly presents himself as worthy of amazement through the seriousness of his silence and through his spirit of life. Already from the beginning of his speech, the teacher justifies his staying close to Alcibiades and ascribes his silence to a 'certain obstacle from the god', the absence of which allows him later on to communicate with the young man. For Socrates would not pursue the life of love in the best way, if that choice and the premature approach to the young man were not

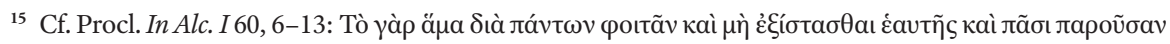

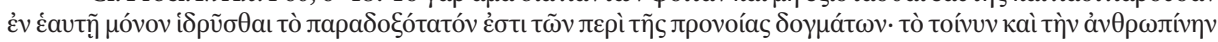

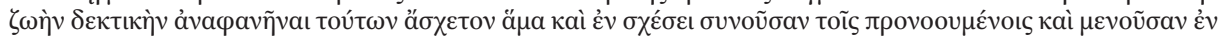

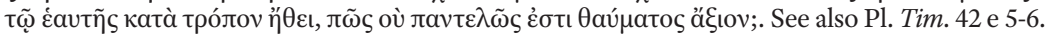


guided by the spirit. ${ }^{16}$ Because love and his interest for him form a work of the providence towards the less complete and because this supervision in a detached, pure and superior way is regarded as an act more divine than any human way of living, Socrates ascribes the cause of the whole of this behaviour to the spirit. The reason is that the achievement of perfection for the inferior and the provision for the lesser belongs to the souls as souls. As also their descent appears due to the providence for things involved in the genesis and due to the care expressed by the mortals. All of the above aim to bring forward results with reference to gods and qualitative people. Thus, it is becomes clear that it does not suits the gods and good spirits to accept anything from those who are controlled by some unethical quality or to allow them to mingle with inferiors, but rather to care for their order. And when a human soul undertakes the role, it takes care to be guided by a divine or spiritual intervention. Hence, also the spirit acts upon the guidance of Socrates and his silence symbolizes the equilibrium, the cessation of the outward deriving activities and his keeping away from the bad life. ${ }^{17}$

\section{Conclusions}

The above examined issues form a minor - yet clear for its directions - sample of the approach offered by Proclus with respect to the question of the educational love. His analyses, his composite judgments and his propositions bring forward a wider branch of anthropology, which is here constituted by the mutual meeting of theoretical and practical reason, within the perspective of the composition of the aesthetic and esoteric, more explicitly of the internal world of a person. Love is not only portrayed as an existential ecstasy, but also as a potential for the transformation of both the lover and the beloved one. Moreover, it is attributed with such a quality that it ranks with the divine. The connection of love to the divine providence forms at the same time also a normative proposition for the humans regarding the way in which they must compose their behavior, the latter having to be a deeply inspired offering towards their fellow beings. Another critical point is that a calm and prudent expression of love is proposed so that it can be demonstrated in an appropriate time and in a proper way, which forms a major issue regarding the educational aims. The fact that Socrates is presented as an exemplar of the divinely inspired lover-educator is a non-negotiable position for Proclus, who argues that the psychological preparation of the persons involved is necessary for the educational

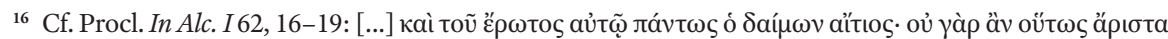

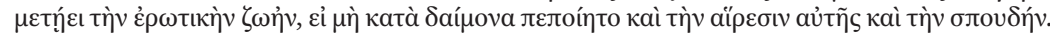

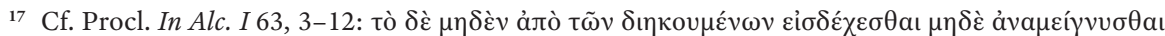

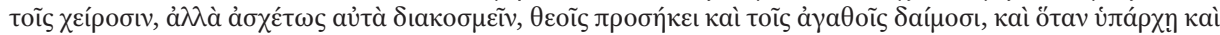

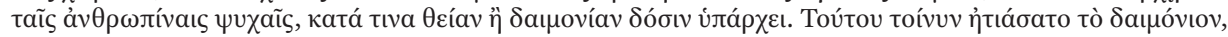

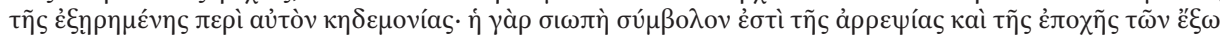

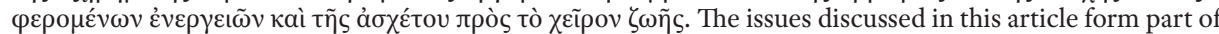
a general branch of anthropology. For the way in which Proclus composes this branch, see Trouillard (1972). 
good to produce qualitative results. The word 'person' is critical, because the paradigm brought forward in all the above discussed issues is basically the education of the person that is realized through the revealing of particularity as a value. Moreover, all the above mentioned issues are connected with the liberal political paradigm of democracy, which does not depend on subjective arbitrariness but on the personal-individual reading of the laws and their application via collective criteria by every specific person. In our opinion, the theoretical propositions of Proclus can constitute a canonic proposition for modern age, since they can surpass the regimentation, self alienation and the unconditional assertion of the quantitatively interpreted schemes of production and result. In other words, they point to the potential of creating a political organization under the inspiration of the Divine republic or under the objective values of the spiritual. 


\section{BIBLIOGRAPHY}

BAstid, P., 1969, Proclus et le crépuscule de la pensée grecque, Paris.

Moutsopoulos, E., 2003, Structure, présence et fonctions du kairos chez Proclus, Athènes.

SEgonds, A.P., 1985, Alcibiades I: Sur le premier Alcibiade de Platon, vol. I, Paris.

Trouillard, J., 1972, L'Un et l'âme selon Proclos, Paris.

CHRISTOS TEREZIS

/Patras /

MARILENA TSAKOYMAKI /Patras /

KEY WORDS

\section{Divine Eros and Divine Providence in Proclus' Educational System}

This study examines the way in which the Neoplatonic philosopher Proclus treats an episode of the dialectic communication between Socrates and Alcibiades in the Platonic dialogue Alcibiades I. More specifically, it refers to how the characteristics and the choices of two different types of lovers - the divinely inspired one and the vulgar one are displayed in the aforementioned text. The characterization 'divinely inspired lover' befits a person who communicates in a pure way with his beloved one and attempts to teach the latter the objective values of the intellect. By contrast, the characterization of the 'vulgar lover' befits that individual that approaches another individual exclusively on the basis of his external beauty. The first type of lover is presented within the realms of the permanently qualitative, while the second as someone who satisfies solemnly his subjectivity and his instincts. Furthermore, it is interesting to note that Proclus argues that Socrates, whom he considers to represent the very definition of a divinely inspired lover, is inspired by divine powers and attempts to act towards to his fellows - in this instance to Alcibiades - in the way through which the divine providence is revealed.

Proclus, Divinely inspired, Vulgar, Divine Providence, Good, Beauty, Lover. 